RECUERDOS DEL

\title{
PRIMER CONGRESO COLOMBIANO DE TERAPIA OCUPACIONAL
}

Patricia Murillo Guerra ${ }^{2}$

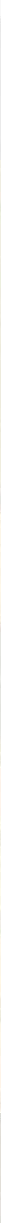

\footnotetext{
1 Terapeuta ocupacional. Docente, Universidad del Valle. Cali, Colombia. patricia.murillo@correounivalle.edu.co (iD) https:/orcid.org/0000-0002-8154-2770

${ }^{2}$ Egresada en 1975, con la tercera promoción de la Escuela Colombiana de Rehabilitación / Universidad del Rosario. Se tituló como licenciada en Terapia Ocupacional. Su recorrido profesional, en sus 47 años de experiencia, lo ha hecho en la ciudad de Cali, Valle del Cauca, Colombia. Inició como terapeuta ocupacional en el Hospital Universitario del Valle y de ahí emprendió un camino por varias instituciones de la ciudad. Ha trabajado en las áreas de rehabilitación física, gerontología, psiquiatría y rehabilitación profesional. Desde 1999 se desempeña como docente de cátedra en la Escuela de Rehabilitación Humana de la Universidad del Valle, donde se ha centrado en la tecnología de asistencia.
} 
En junio de 1978 se realizó el primer Congreso Colombiano de Terapia Ocupacional. La propuesta surgió de la Asociación Colombiana de Terapia Ocupacional, que, desde su creación en 1972, organizaba eventos cortos de capacitación para sus afiliadas, en los que se manejaban temas puntuales. Para ese año, la Asociación consideró que era hora de ofrecer un evento nacional en el cual se expusieran variados asuntos de interés. Convocó entonces al grupo de terapeutas que trabajábamos en esa época en Cali, con la idea de organizarlo en esta ciudad.

Así fue como hicimos equipo ocho terapeutas ocupacionales radicadas en Cali y, con el acompañamiento de la Asociación, iniciamos las acciones para llevar a buen término el reto de organizar nuestro primer evento nacional: ¡el Primer Congreso Colombiano de Terapia Ocupacional!

Norma Rivas, egresada de la Universidad Nacional de Colombia, tomó las riendas del grupo. Empezamos a trabajar meses antes buscando patrocinios, espacios adecuados para desarrollar la agenda científica y los eventos sociales -colaterales, pero no menos importantes-, y los equipos de comunicación necesarios en esa época: proyector de diapositivas y micrófono. Invitamos a una terapeuta ocupacional de Estados Unidos (figura 1), lo que nos obligaba a contratar el servicio de traducción simultánea, y a otras expertas y expertos de Colombia, para quienes debíamos garantizar una estadía a la altura de las circunstancias. 
Figura 1. Carta de invitación a la ponente estadounidense Shirley Ollos Pearson

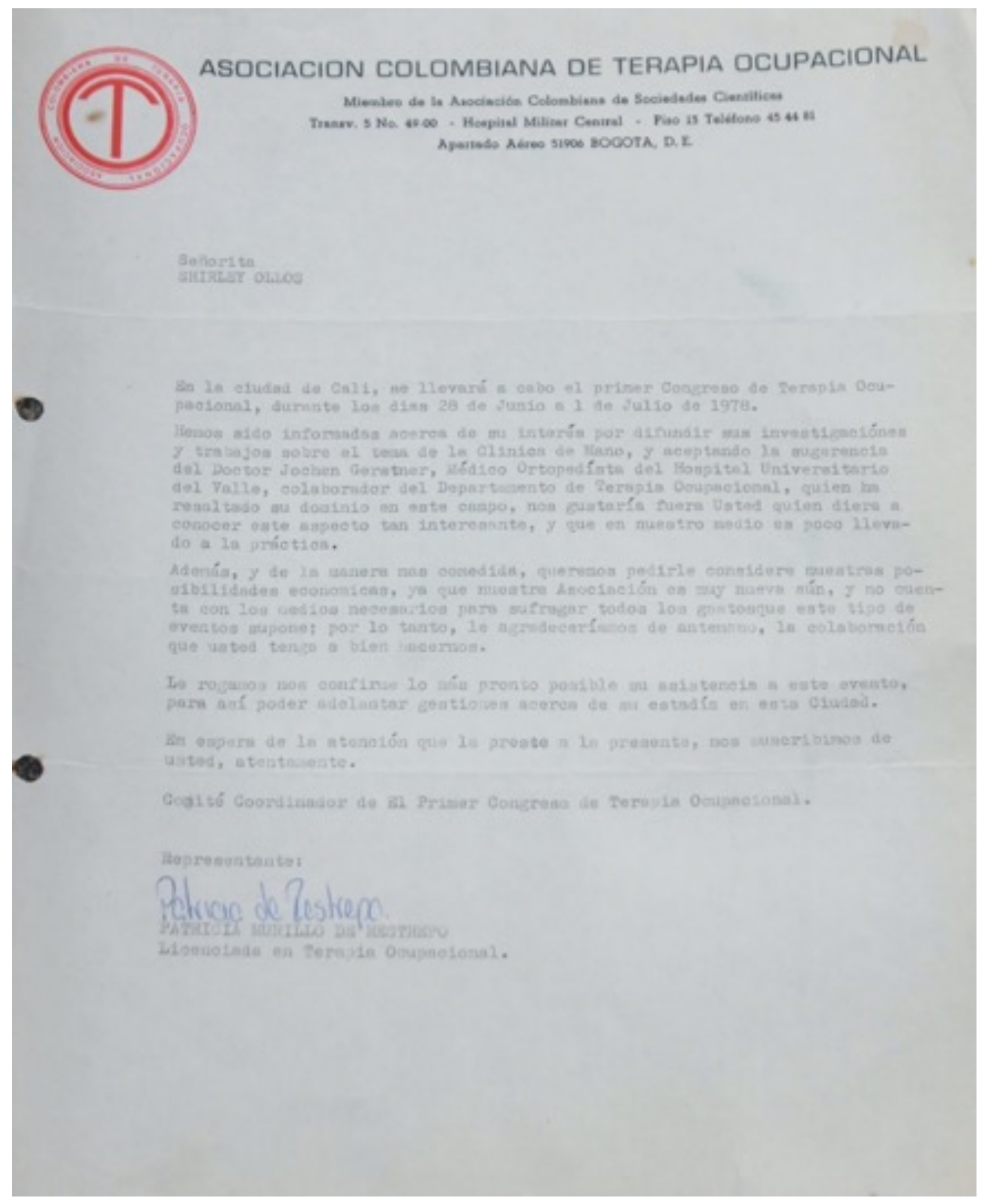

Fuente: archivo personal de la autora, donado a la muestra museográfica Historias de Terapias Ocupacionales en Colombia. 
Norma contaba con un entusiasta grupo, dispuesto a sacar adelante el Congreso: María Helena Vega, egresada de la Universidad Nacional de Colombia; Patricia Montealegre y Ana Benilda Romo, egresadas de la Escuela Colombiana de Rehabilitación / Universidad del Rosario; Aida Paz, Marta Arango y Beatriz Giraldo, también de la Universidad Nacional, y yo, Patricia Murillo, egresada de la Escuela Colombiana de Rehabilitación / Universidad del Rosario.

El Congreso se inauguró el miércoles 28 de junio de 1978 con un coctel de bienvenida en el Club San Fernando. Al día siguiente, iniciamos las actividades científicas (figura 2), que se realizaron en el Salón del Consejo del Centro Administrativo Municipal (CAM).

Recuerdo especialmente a la invitada internacional y a un médico fisiatra que vino desde Medellín. Shirley Ollos Pearson, terapeuta ocupacional del Jackson Memorial Hospital de Miami, era la ponente internacional. Vino a hablarnos de rehabilitación de mano y a mostrarnos una novedad del momento en la elaboración de órtesis a nivel mundial: los termoplásticos de baja temperatura. Recuerdo nuestra extrañeza cuando nos pidió llevar al escenario una estufa para mantener un recipiente con agua caliente... y nuestra enorme sorpresa al ver cómo, con esa agua caliente, manipulaba el material.

Ese primer contacto con los termoplásticos de baja temperatura, particularmente para quienes trabajábamos en el área de la tecnología, ¡fue revelador! Ver cómo hacía una ortesis básica en una hora, con un equipo mínimo y tan buenos resultados, nos permitió compararlo con el proceso largo y dispendioso que llevábamos a cabo en nuestros talleres a partir de tubos de PVC. Definitivamente, cambió en el corto plazo nuestra manera de hacer órtesis.

Alberto Correa Cadavid, médico fisiatra de Medellín, otro de nuestros invitados, nos mostró cómo aplicar la musicoterapia en procesos de rehabilitación. Pero lo que más recuerdo de sus intervenciones y de las conversaciones que pudimos tener a lo largo del evento fue su visión del terapeuta ocupacional trabajando con la comunidad. No concebía a una o a un terapeuta ocupacional en un consultorio, menos detrás de un escritorio. Insistió en que nuestro lugar estaba en la casa de la persona, con su familia, en su entorno, que debíamos tener las "botas siempre puestas". Para esa época, era un discurso de avanzada.

El sábado 1 de julio, ofrecimos un almuerzo de clausura en el Club Águila Roja (figura 3). Este fue patrocinado por Grajales Hermanos y Café Águila Roja. Con ese evento y, luego, un recorrido por la ciudad, cerramos el Congreso. 
Figura 2. Programa preliminar del Primer Congreso Colombiano de Terapia Ocupacional

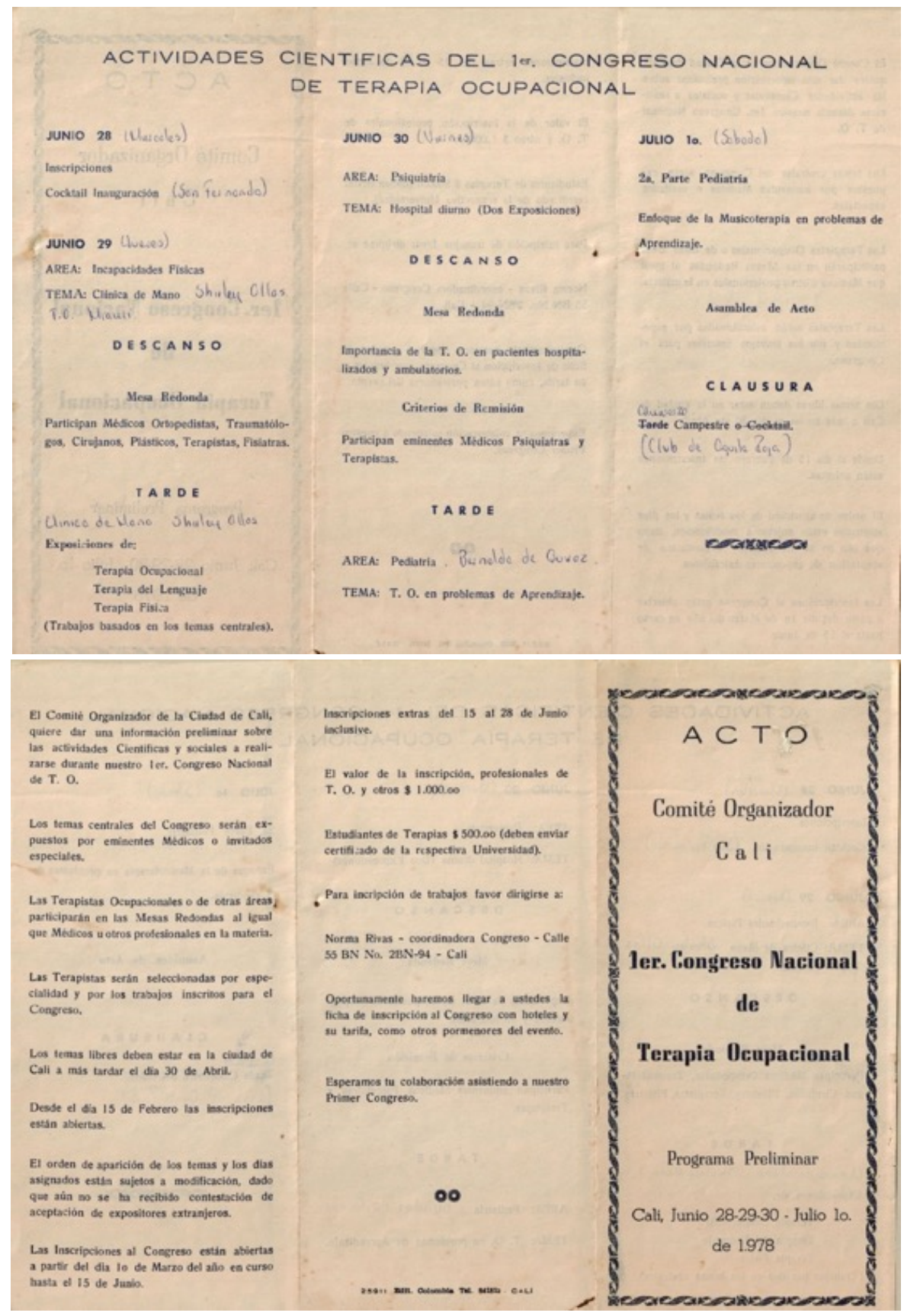

Fuente: archivo personal de la autora, donado a la muestra museográfica Historias de Terapias Ocupacionales en Colombia. 
Figura 3. Invitación a la clausura y escarapela del Congreso

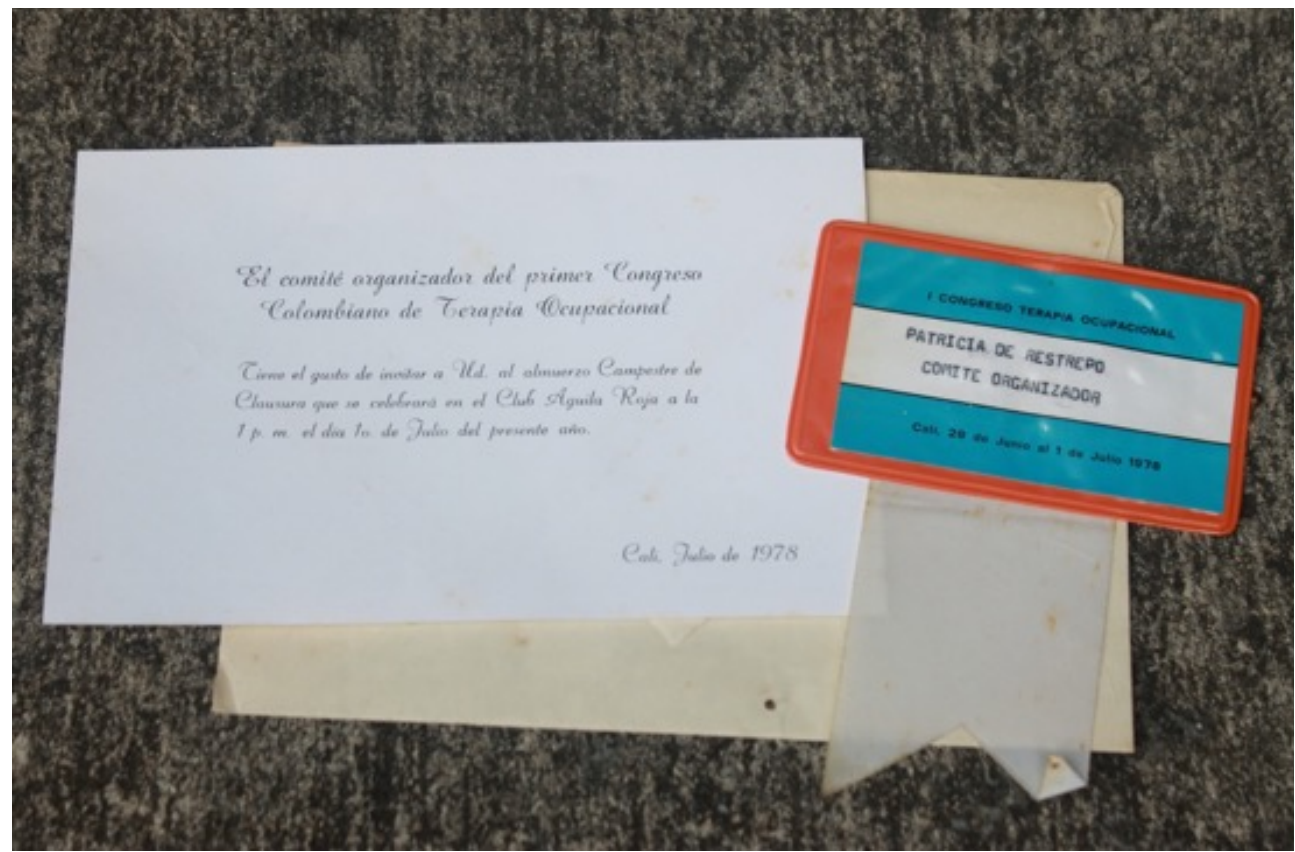

Fuente: archivo personal de la autora, donado a la muestra museográfica Historias de Terapias Ocupacionales en Colombia. 